\title{
Classifying Indian Medicinal Leaf Species Using LCFN-BRNN Model
}

\author{
Kiruba Raji $\mathbf{I}^{{ }^{*}}$, Thyagharajan K.K ${ }^{2}$, Vignesh $\mathrm{T}^{3}$ and Kalaiarasi $\mathbf{G}^{4}$ \\ ${ }^{1}$ Department of CSE, R.M.D Engineering Collège, Chennai, India \\ [e-mail: kiruba161107@gmail.com] \\ ${ }^{2}$ Department of ECE, R.M.D Engineering Collège, Chennai, India \\ [e-mail: kkthyagharajan@yahoo.com] \\ ${ }^{3}$ Department of Master of Computer Application \\ SRM Institute of Science and Technology, \\ Ramapuram,Chennai,India. \\ [e-mail: vigneshthangathurai@gmail.com] \\ ${ }^{4}$ Department of Computer Science and Engineering, \\ Sathyabama Institute of Science and Technology, Chennai, India \\ [e-mail: kalaiarasi.cse@sathyabama.ac.in] \\ *Corresponding author: I. Kiruba Raji
}

Received April 4, 2021; revised June 14, 2021; accepted August 1, 2021; published October 31, 2021

\begin{abstract}
Indian herbal plants are used in agriculture and in the food, cosmetics, and pharmaceutical industries. Laboratory-based tests are routinely used to identify and classify similar herb species by analyzing their internal cell structures. In this paper, we have applied computer vision techniques to do the same. The original leaf image was preprocessed using the ChanVese active contour segmentation algorithm to efface the background from the image by setting the contraction bias as (v) -1 and smoothing factor $(\mu)$ as 0.5 , and bringing the initial contour close to the image boundary. Thereafter the segmented grayscale image was fed to a leaky capacitance fired neuron model (LCFN), which differentiates between similar herbs by combining different groups of pixels in the leaf image. The LFCN's decay constant (f), decay constant (g) and threshold (h) parameters were empirically assigned as 0.7, 0.6 and $\mathrm{h}=18$ to generate the $1 \mathrm{D}$ feature vector. The LCFN time sequence identified the internal leaf structure at different iterations. Our proposed framework was tested against newly collected herbal species of natural images, geometrically variant images in terms of size, orientation and position. The 1D sequence and shape features of aloe, betel, Indian borage, bittergourd, grape, insulin herb, guava, mango, nilavembu, nithiyakalyani, sweet basil and pomegranate were fed into the 5-fold Bayesian regularization neural network (BRNN), K-nearest neighbors (KNN), support vector machine (SVM), and ensemble classifier to obtain the highest classification accuracy of $91.19 \%$.
\end{abstract}

Keywords: Chan-Vese segmentation, Leaky Capacitance and Fired Neuron (LCFN), time sequence, Bayesian Regularization Neural Network (BRNN), computer vision 


\section{Introduction}

Medicinal plants include the different types used in herbology. The word herb was originally used to refer to non-woody plants but has since evolved to include stems, roots, bark, leaves, and flowers. Medicinal plants cure disease and herbal medicine is deemed safe, with minimal or no side effects. Herbs can be used to treat people across all age groups.

Medicinal plants offer the ingredients necessary to prepare Ayurvedic, Unani and Siddha medication as well as an array of synthetic drugs. Medicinal plants are widely used in diverse cultures around the world. Certain herbs are used as nutrient supplements owing to their therapeutic values, and in perfume, natural dyes and pesticide control. They heal wounds and boils and are used as blood purifiers, antibiotics and antacids that aid in digestion. In ancient India, herbs were used to treat snake bites in particular and animal bites in general. Certain herbs are used as nutrient supplements owing to their therapeutic values, and in perfume, natural dyes and pesticide control. They heal wounds and boils and are used as blood purifiers, antibiotics and antacids that aid in digestion. In ancient India, herbs were used to treat snake bites in particular and animal bites in general. Medicinal plants are used in agriculture and the preparation of essential oils, and give the economy a huge boost as well. Several species of herbs are used as preservatives, while others have replaced artificial color in the food industry. Medicinal and aromatic plants are used as food supplements and in the preparation of candy and cosmetics. The classification of medicinal herbs is, however, a challenge.

The classification of medicinal plants is necessary, from a pharmacological point of view, because medicines are derived from plants and microbes. The earth contains more than 5,00,000 botanical species like algae, fungi, lichens, liverworts, mosses, ferns, conifers and flowering plants. The International Code of Botanical Nomenclature [1] has provided various taxonomic ranks in botanical classification, including genus, family, order, class, division, subdivision and kingdom. Plant taxonomy comprises three types of plant classification systems - artificial or mechanical, natural and phylogenetic. The artificial or mechanical plant classification system comprises one or a few characters to group taxa, while the natural system contains numerous characters to classify plants and the phylogenetic system recognizes the evolutionary relationship among taxa. Botanists identify medicinal plants through their anatomical or morphological structural characteristics. A complete plant specimen is needed for a morphological analysis to be carried out before herbal drugs can be identified and extracted. However, of the two, an anatomical structural analysis works best at plant identification and authentication, though it is a time-consuming process. An anatomical structure analysis examines a plant's internal structure, particularly cell structure, through light microscopy. However, such an analysis calls for superior knowledge of plant cellular structure [2]. To resolve the problems above faced by pharmacologists and practitioners of Ayurveda, Unani and Siddha with regard to herbal plants, an efficient plant species classification tool using computer vision techniques is the need of the hour.

Arun et al. (2017) [3] proposed an optimized color channel and texture models to classify medicinal leaves native to Kanyakumari district in the state of Tamil Nadu in India. Only five species of medicinal leaves were considered, totalling 250 images in all. Their findings showed that leaf color varies as a result of climate change, bacteria and fungus. Naresh et al. (2016) [4] introduced a modified local binary pattern (MLBP) technique to extract medicinal leaf features from the UoM Medicinal Plants Dataset, using the nearest neighbor classifier. Shitole et al. (2019) [5] used morphological shape features to classify leaves and tested their system with only five different species of plants. Xue et al. (2019) [6] used the geometric features of leaves to classify 20 different Chinese medicinal plants. 
Hamid et al. (2017) [7] used the leaf quartile feature to handle high interclass similarity between different plant species. Leaf images were aligned, with their model supporting rotational invariance. Aakif et al. (2015) [8] utilized morphological leaf shape features to classify plants and applied different normalization techniques for rotation and translation invariances. Chaki et al. (2018) [9] exploited shape, color and texture features for plant classification, utilizing a significant number of features to classify plants in different hierarchical structures. Clark et al. (2017) [10] and Wang et al. (2019) [11] employed leaf tooth features to classify herbarium data, a process complicated by damage to the leaf teeth. Souza et al. (2016) [12] used multiscale bending energy (MBE) descriptors to classify plants, applying optimization techniques for feature selection, given that the MBE provides numerous features at different scales. Kolivand et al. (2019) [13] employed venation-based morphological features, though the venation patterns are undefined in some leaves and the computational time of the venation feature is high. Turkoglu et al. (2019) [14] exploited texture features using a local binary pattern of the red and green pixels of the leaves. Zhang et al. (2020) [15] used global and local leaf margin features to classify plant species. Thyagharajan et al. [16] reviewed an array of visual descriptors and classifiers used in leaf species classification.

Plants are a major source of ingredients in the preparation of herbal medicine. Every part of certain plants, including the root, stem, leaf, seed and flowers, is used to this end. Leaves are two-dimensional objects with indubitable therapeutic properties and are non-seasonal. A key issue with the digitization of herbal plants is the selection of sources from every part of a plant. The leaf [7-9] is a critical component of the medicinal plant species classification system. Leaves are used to extract domain-specific features such as shape, venation details, base and apex shapes and, finally, leaf types.

Computer vision techniques are applied to design a medicinal plant species classification system by extracting geometric, morphological and shape features from medicinal leaves. Morphological features alone, however, are not enough to classify leaves. Rather, all leaf features are to be extracted. This is because numerous inter-class species look the same in terms of leaf and base shapes as well as vein arrangement. Traditionally, attempts have been made to resolve the problem by analyzing the internal cell structure of leaves using the light intensity microscopic technique. An efficient computer vision-based medicinal leaf classification system is needed to differentiate between inter-species leaf similarity. Such a system aligns leaf images to remove image invariances. In this paper, we propose the LCFN model, which utilizes the biological characteristics of the PCNN [17] . The LCFN has distinctive characteristics. It is a simpler version of the PCNN, contains fewer parameters and is computationally fast. The number of neurons in the LCFN is equal to the size of the image and the network size changes dynamically, depending on image size. It detects distinct interspecies quickly, using pulse signals by grouping different neurons in each iteration. The LCFN model increases the speed at which neurons are fired by reducing the input with each iteration. It operates on images that contain no straight lines and on those with weak edges. The model supports translation, rotation and scaling invariance. Further, separate normalization and dimension reduction techniques are not called for. Image features are easily extracted using the LCFN, without their being aligned [2-5].

Distinguishing between herbal leaves requires an in-depth analysis of their shape, vein patterns and color, along with a combination of machine learning methods to achieve the best results.Our chief contributions towards resolving this problem are

i. to propose an LCFN model that combines different groups of pixels to extract different types of features in each iteration. 
ii. to extract rotational-, scale- and transform-invariant features that demand no augmented images.

iii. to improve feature quality using the Chan-Vese active contour segmentation algorithm.

iv. to evaluate the extracted features using the 5-fold Bayesian regularization neural network (BRNN), K-nearest neighbors (KNN), support vector machine (SVM) and an ensemble classifier, and compare the recognition accuracy produced by each classification method.

v. to create an Indian Medicinal Leaf Species Dataset containing a total of 635 images.

\section{Materials and Methods}

\subsection{The Herbal Dataset and its Classification}

Medicinal plants are categorized on the basis of their use, active constituents life cycle and botanical classification. Based on their particular uses, herbs are divided into four classes medicinal, culinary, aromatic and ornamental. Medicinal herbs are used in the preparation of medicine, culinary herbs in cooking, aromatic herbs for their pleasant smell and ornamental herbs for decor. They are further divided into aromatic, astringent, bitter, mucilaginous and nutritive, based on their active constituents. Astringent herbs are used as antiseptics; bitter herbs as antibiotics; mucilaginous herbs as digestives, producing a sweet taste when added to water, owing to their polysaccharide content, and nutritive herbs add restorative value to the diet. They are further divided into aromatic, astringent, bitter, mucilaginous and nutritive, based on their active constituents. Astringent herbs are used as antiseptics; bitter herbs as antibiotics; mucilaginous herbs as digestives, producing a sweet taste when added to water, owing to their polysaccharide content, and nutritive herbs add restorative value to the diet. Based on their life cycle, herbs are classified as annuals, biennials and perennials. Our dataset comprises 635 images of herbal leaves such as aloe, betel, Indian borage, bittergourd, grape, insulin herb, guava, mango, nilavembu, nithiyakalyani, sweet basil and pomegranate, collected from southern Tamil Nadu. These images are divided, depending on their use, into medicinal, culinary, aromatic and ornamental herbs.

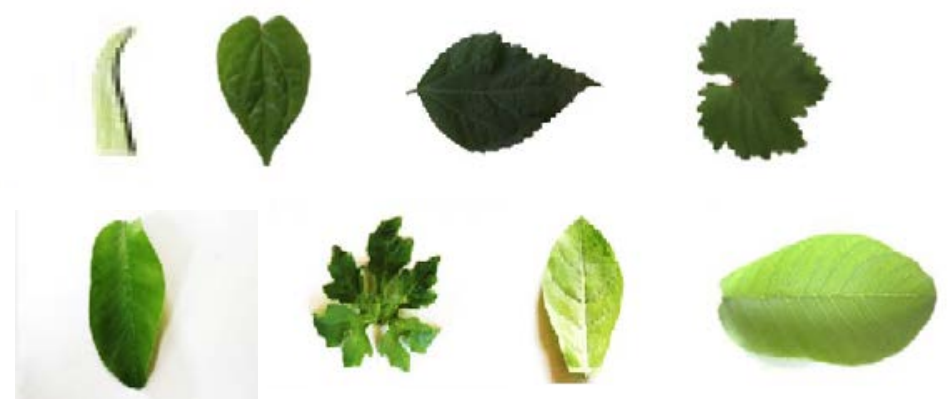

Fig. 1. Sample medicinal species

The medicinal plants in Fig. 1 are identified through the morphological properties of leaves and their uses. However, certain herbal plants are similar in their morphological, physiological and biochemical characteristics. The morphological and chemical compounds of medicinal plants share an intrinsic relationship. Traditional laboratory-based plant classification methods are expensive and laborious. Medicinal plants are to be digitized to conserve them, and herbs are to be identified quickly by pharmacologists and doctors through an examination of their 
leaves. Researchers today use image processing and computer vision techniques to protect herbs.

\section{The Proposed System}

Fig. 2 shows the flow diagram of the proposed system, which consists of the three stages of segmentation, feature extraction and classification. Each processing stage is discussed below.

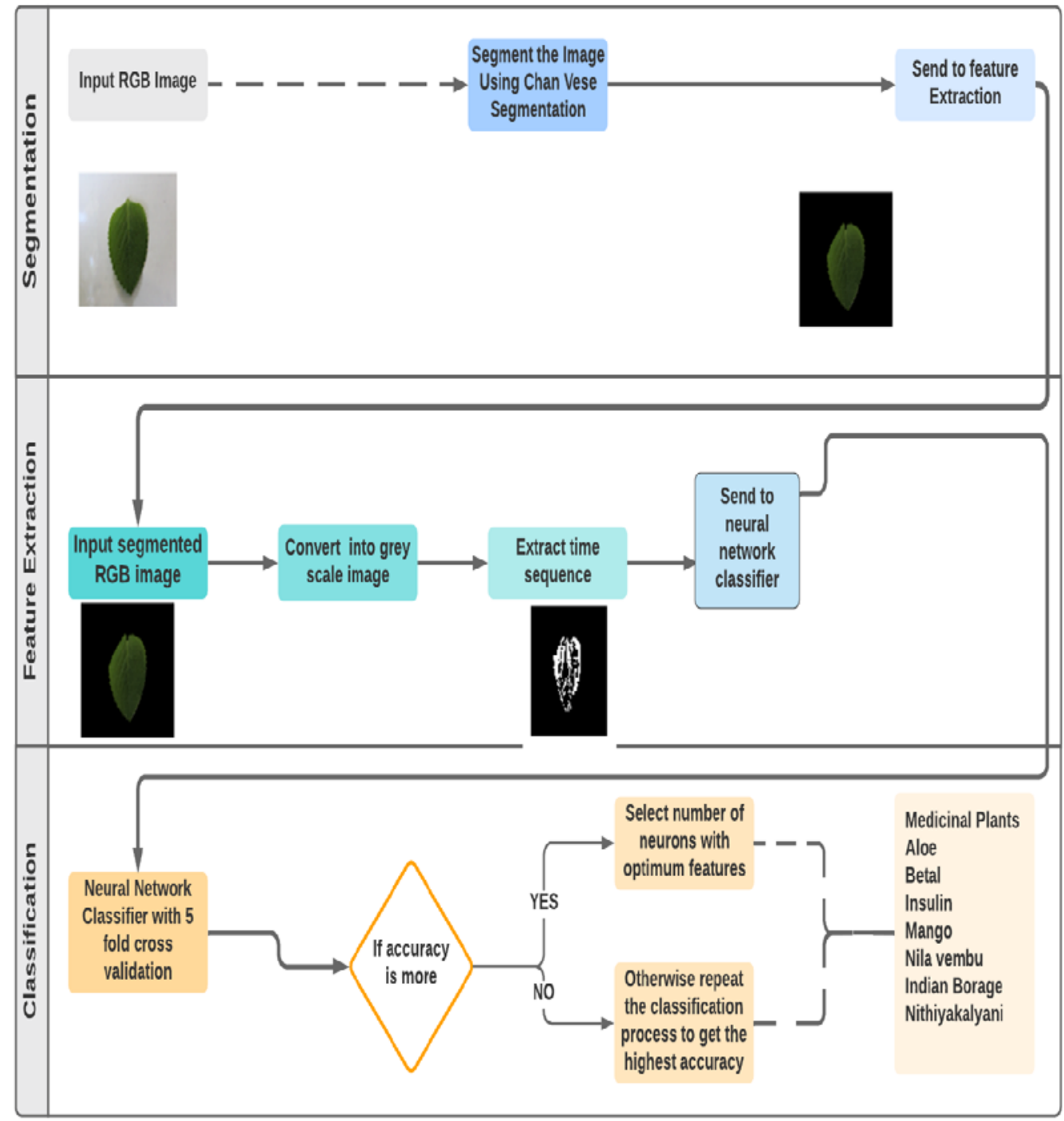

Fig. 2. Medicinal plant species classification system 


\subsection{The Chan-Vese Segmentation Algorithm}

Image quality may vary, depending on image acquisition devices and how the image is captured. The segmentation process distinguishes the leaf image from its background. All the images captured in the Medicinal Leaf Database depict a transparent background. Background removal is indispensable to the process because the LCFN of the PCNN works, based on the intensity of the image pixels. Interference is a problem in the LCFN since it includes background pixels in its 1D time sequence. Consequently, the region-growing active contour model [18],[19],[20] is applied to separate the target medicinal leaves from their background by moving the initial contour of the leaf image towards the boundary of the object.The region growing active contour algorithm ([21],[22]) is defined in (1)

$$
\begin{aligned}
F\left(c_{1}, c_{2}, C\right)= & \mu . \text { length }(C)+v \cdot \text { Area }(\text { inside }(c)) \\
& +\lambda_{1} \int_{\text {inside }(C)}\left|\varphi_{0}(x, y)-c_{1}(x, y)\right|^{2} d x d y \\
& +\lambda_{2} \int_{\text {outside }(C)}\left|\varphi_{0}(x, y)-c_{2}(x, y)\right|^{2} d x d y
\end{aligned}
$$

In this algorithm, $\mu$ (smoothing factor) is a scaling factor that should be small because the herbal database contains clear leaf images with simple backgrounds. Here, $\varphi_{0}$ is a given image, $\mathrm{C}$ the evolving contour of the image, $\mathrm{c}_{1}$ the average value of $\varphi_{0}$ where $\varphi \geq 0$, and $\mathrm{c}_{2}$ the average value of $\varphi_{0}$ outside the given image where $\varphi \leq 0 . \mu$ is the smoothing factor and $\mathrm{v}$ the contraction bias. The variable 'Area' is the area of curve $C$ and $\lambda$ is the fit weight. The constants $\lambda_{1}$ and $\lambda_{2}$ are fit weights, and the values of $\lambda 1$ and $\lambda_{2}$ are assigned 1 . The Chan-Vese parameter setting is explained below.

\subsubsection{Parameters used in the Chan-Vese Algorithm}

1. Initial contour: An initial circular, square or rectangular-shaped mask is assigned close to the image boundary. In our work, the initial mask is square-shaped because of the differently shaped leaves. The initial contour mask should be adjacent to the image boundary.

2. Contraction bias (v): The contraction bias decides the orientation of the initial contour, and the direction of movement depends on the initial contour, that is, the contour shifts either inside or outside the square. If the initial contour mask is close to the image boundary, the negative values of the contraction bias expand the initial contour until it reaches the image boundary. If the initial contour is larger than the boundary, we set the contraction bias as positive. The contraction bias shrinks the contour inside the image boundary. The value of the contraction bias is between -1 and +1 .

3. Smoothing factor $(\mu)$ : The smoothing factor provides exceptional details of the leaf boundary. A large smoothing factor produces fine details of the leaf image boundary, while a small one results in irregular boundaries. In leaf image segmentation, we need an irregular leaf boundary; otherwise, all the leaf images look identical.

4. Iteration number: This parameter produces boundary convergence details. If the initial contour is close to the image boundary, the number of iterations is equal to the image width or height. If the initial contour is far from the boundary, the number of iterations is high. 


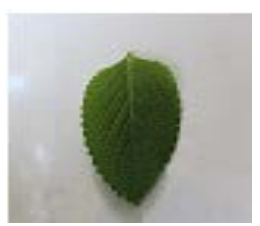

(a). Original $(800 \times 600 \times 3)$

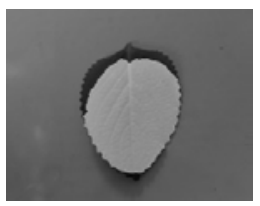

(e). Iteration 400 $(800 \times 600)$

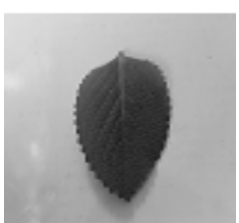

(b). Gray $(800 \times 600)$

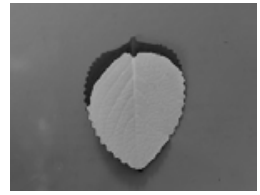

(f). Iteration 600 $(800 \times 600)$ $\mathrm{F}_{1}\left(\mathrm{C}_{1}\right)=0$ and $\mathrm{F}_{2}\left(\mathrm{C}_{2}\right)>0$

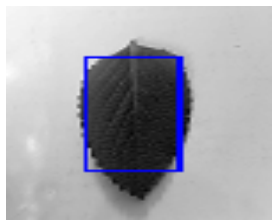

(c). Initial Contour $(800 \times 600)$ $\mathrm{F}_{1}\left(\mathrm{C}_{1}\right)=0$ and $\mathrm{F}_{2}\left(\mathrm{c}_{2}\right)>0$

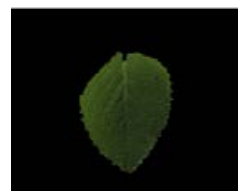

(g). Segmented Image $(800 \times 600 \times 3)$

$\mathrm{F}_{1}\left(\mathrm{C}_{1}\right)=0$ and $\mathrm{F}_{2}\left(\mathrm{C}_{2}\right)=0$

Fig. 3. Evolving contour 'C' using the Chan-Vese segmentation algorithm

$$
\begin{gathered}
\text { Evolving }(C)=\text { Inside }(C)+\text { Outside }(C) \\
F(C)=F_{1}\left(c_{1}\right)+F_{2}\left(c_{2}\right) \\
\text { where } F_{1}\left(c_{1}\right)=\lambda_{1} \int_{\text {inside }(C)}\left|\varphi_{0}(x, y)-c_{1}(x, y)\right|^{2} d x d y \\
F_{2}\left(c_{2}\right)=\lambda_{2} \int_{\text {outside }(C)}\left|\varphi_{0}(x, y)-c_{2}(x, y)\right|^{2} d x d y
\end{gathered}
$$

Fig. 3(a) shows the input image with a pixel size of $800 \times 600 \times 3$ and Fig. 3(b) the grayscale image with a pixel size of $800 \times 600$. The contour evolution is executed according to Equations (2) and (3). The initial contour, sized [200,200,200,200], is close to the image boundary (Fig. 3(c)). The contraction bias, which is set at -0.1, expands the initial contour close to the herbal leaf image boundary, as in Fig. 3(d).-3(f). The smoothing factor is 0.5, because irregular leaf margin details are needed to differentiate between the herbal leaves (Fig. 3(d)- 3(f)). The number of iterations is 600, which is equal to the width (Fig. 3(f)), because the initial contour is close to the image boundary. Fig. 3(d) - 3(f) shows the movement of the initial contour, according to Equations (4) and (5). Though the contour is inside the image, the position of the contour should satisfy the condition $\left(\mathrm{F}_{1}\left(\mathrm{C}_{1}\right)=0\right.$ and $\left.\mathrm{F}_{2}\left(\mathrm{C}_{2}\right)>0\right)$, that is, the area of the outside contour of the image boundary is greater than zero while that of the inside contour of the same is equal to zero. This process is repeated until the curve " $\mathrm{C}$ " reaches the image boundary at equilibrium, which is $\mathrm{F}_{1}\left(\mathrm{C}_{1}\right)=0$ and $\mathrm{F}_{2}\left(\mathrm{C}_{2}\right)=0$, and continues until it reaches the image boundary. Fig. 3(g) shows the segmented image.

\subsection{Feature Extraction}

Images are collections of pixels. Each image has multiple pixels, depending on the width and height of the image. The Chan-Vese region growing active contour segmentation algorithm segments the leaf image from the background. The segmented image cannot be used directly because it contains a significant number of pixels, and all the pixel information needed to classify the herbs does not need to be stored. The distinct properties of the herbal leaf image, such as shape and texture, as well as geometrical and morphological features, are used. We 
use the LCFN model of the PCNN to extract various features of the herbs, not perceived by humans, in each iteration.

\subsubsection{Leaky Capacitor- Fired Neuron}

We propose a new LCFN with the pulse-coupled neural network (PCNN). The PCNN was first proposed by [23] and derived from a pig's visual cortex model. The original model used a leaky integrator synapse, but we use a leaky capacitance model that simplifies the design to improve firing speed. The feeding input of the synapse is given in (6). Here, the input is divided with the initial ' $n$ ' at a constant rate to speed up the neuron's firing.

$$
S_{i j}(n)=S_{i j}(n-1) / n
$$

$S_{i j}(n)$ denotes a change in the leaky capacitor at the $\mathrm{n}^{\text {th }}$ instant of the time involved. The initial value, $S_{i j}(0)$, is the value of the pixel at the $0^{\text {th }}$ location, and represents the capacitor's initial charge, that is, the value at the $0^{\text {th }}$ iteration, which is $S_{\mathrm{ij}}(\max )$. The neuron receives an input signal through the feeding synapse. The linking synapse connects a neuron to its 8 neighbors and modifies the output signal based on the values of the neighboring pixels. Thus, a neuron's internal activation unit contains a leaky capacitor that discharges through a constant circuit and a linking input. The internal activation unit is shown in (7).

$$
U_{i j}(n)=f U i j(n-1)+\sum_{i j} M_{k l} Y_{i j}(n-1)+S_{i j}(n-1)
$$

$U_{i j}(n)$ denotes the output of the internal activation unit, of which the constant, ' $\mathrm{f}$ ', is the linear decay.

The ' $\mathrm{k}$ ' and ' $\mathrm{l}$ ' values are indices of the neighboring neurons and $M_{k l}$ is the weight value assigned to the neuron's output, $Y_{i j}$.

The dynamic threshold value, $T_{i j}$, of the neuron positioned at the $\mathrm{i}, \mathrm{j}$ indices decreases with the decay time constant, ' $g$ ', in each iteration. The dynamic threshold equation is shown in (8).

$$
T_{i j}(n)=g T_{i j}(n-1)+h Y_{i j}(n-1)
$$

The constant, ' $h$ ', is a threshold that decides the neuron's output for setting the current threshold.

When a neuron's internal activation unit, $U_{i j}(n)$, exceeds the dynamic threshold, $T_{i j}(n)$, the neuron fires and an output pulse, $Y_{i j}(n)$, is produced. The generation of the pulse by each neuron is given by (9)

$$
Y_{i j}(n)= \begin{cases}1 & \text { if } U_{i j}(n)>T_{i j}(n) \\ 0 & \text { otherwise }\end{cases}
$$

Equation (10) gives the time sequence of the image obtained with the optimum value network parameters.

$$
G(n)=\sum_{i j} Y_{i j}(n)
$$

Here G(n) represents the time sequence of the pulse image signature. The LCFN generates pulse images based on the time (iterations), and the pulse images display segments, edges and textures from the input image. This network produces better results than others, though computation time is extended on account of its sequential nature. The LCFN model supports 
translation, scale and rotation-invariant features. Each neuron group with different neurons depends on the image patches, and since the time sequence contains the amplitude and frequency, the need to apply normalization techniques is dispensed with.The geometrical content of the image and its intensity is encoded in the time signal [24]. The time sequence is object-specific, and two-dimensional images can be represented as a 1-dimensional signature, thereby reducing the memory of the image data and facilitating its processing as far as possible.

\subsubsection{Analysis of LCFN Parameters and their Features}

Initially, we set the membrane potential at $(\operatorname{Uij}(0))=0$ and the threshold at $\theta i j(0)=1$. When $\operatorname{Uij}$ $>\theta \mathrm{ij}$, the resultant action potential is $\mathrm{Yij}=1$ and, thus, $\mathrm{f}>\mathrm{g}$. That is, to ensure a larger Uij decay, the dynamic threshold is required to drop to $\theta \mathrm{ij}$ and the decay constants ( $\mathrm{f}$ and g) should be less than 1 to produce the step input. The neuron firing rate of the proposed system is linked to pixel brightness. A neuron is triggered, based on its unique input and the state of the neighboring neurons. If a single neuron fires, it triggers the entire group and determines the different input image regions. With the increasing value of iteration "n," the value of the dynamic threshold ( $\theta \mathrm{ij}$ ) decreases, and the value of $\mathrm{h}$ must be larger for all the neurons in the herbal leaf to be fired at once. Hence, ' $g$ ' and ' $f$ ' should be set between $0<{ }^{\prime} f$ ',' $g$ ' $<1$. The action potential, Yij, rises with the increasing value of the threshold, (h). However, for this experiment, the values of 'f,' ' $g$,' and ' $h$ ' are set at $0.7,0.5$ and 18, respectively. These settings produce good feature extraction results, as shown in Fig. 4(a) and Fig. 4(b). Each iteration fires different groups of neurons and hence extracts different features.

The binary images extracted contain feature information about the leaf. The features extracted by the NLIF at different iterations are also shown in Fig. 4(b). The binary image in iteration (n)=3 extracts the contours of the leaves. However, the iteration number that extracts contours for all the leaves need not be 3 . For some leaf images, veins may appear in certain iterations. The vein details of the leaf are extracted in iteration 4, as shown in Fig. 4(b) (ii), when $\mathrm{f}=0.7, \mathrm{~g}=0.6$ and $\mathrm{h}=18$. Similarly, other iterations extract features that cannot be easily interpreted by humans. We select time sequence features based on the firing mechanism and the grouping of white pixels. The previously used algorithm [1-4] in leaf species classification extracts the shape, vein, tip, base and margin features separately.

It is an extremely tedious process to establish, approximately, the venation pattern or leaf base. However, time sequence features automatically generate images of the next pulse, based on the neighboring pixel predictions of the neuron. Therefore, it automatically generates the next feature, which makes it easy to identify the finer details of the leaf. Time sequencing facilitates the continuous processing of input stimuli and requires little time for feature computation.

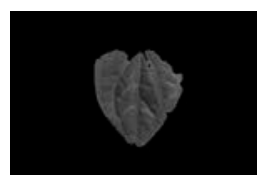

Fig. 4. (a). Original Image

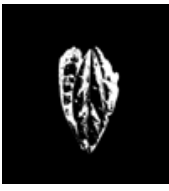

(i). $n=3$

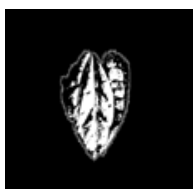

(ii). $\mathrm{n}=4$

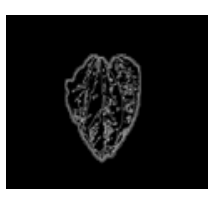

(iii). $\mathrm{n}=12$

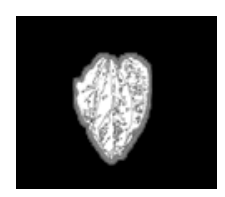

(iv). $\mathrm{n}=15$

Fig. 4. (b). Pulse Images Obtained by LCFN Model when $\mathrm{f}=0.7$, $\mathrm{g}=0.6$, and $\mathrm{h}=18$ 
A smaller leaf of the same species produces a binary image with a smaller number of pixels. In every iteration, we compute the total number of white pixels as the feature and normalize it to the leaf area, as in (11).

$G(n)=\sum_{i j} \frac{\left(Y_{i j}(n)\right)}{\text { area of leaf in pixels }}$

Here, G(n) represents the normalized value of the feature obtained in iteration "n." A sequence of such values obtained in consecutive iterations forms the time sequence of the specific leaf and is the feature vector produced by the LCFN for the particular leaf object.

\subsubsection{Features Extracted by the LCFN}

Symmetries in the receptive field of any two-portion weights are the same, and the exchange of the receptive field weight values does not affect input image changes. The neuron's output depends on the internal activity (Uij) of the LCFN, and internal activity is a function of linking inputs. If the image change depends on the translation, rotation and scale values, the neuron's internal activity does not change and the output of the neuron is invariant against the changes. In translational invariance, every neuron utilizes the same weight pattern. In rotational invariance, the weight pattern changes to the circularly symmetric. In scale invariance, the weights are arranged according to the inverse square rule. The intensity of the image pixel is constant, affecting only scale changes in the original image. Accordingly, we align the weights as circularly symmetric, with the radius $r=2$. The intensity of the image pixel is constant, affecting only scale changes in the original image. Accordingly, we align the weights as circularly symmetric, with the radius $r=2$. Fig. 5 shows the same time sequence in translation, rotation and variance in scaling.

\section{Geometrical Invariances}

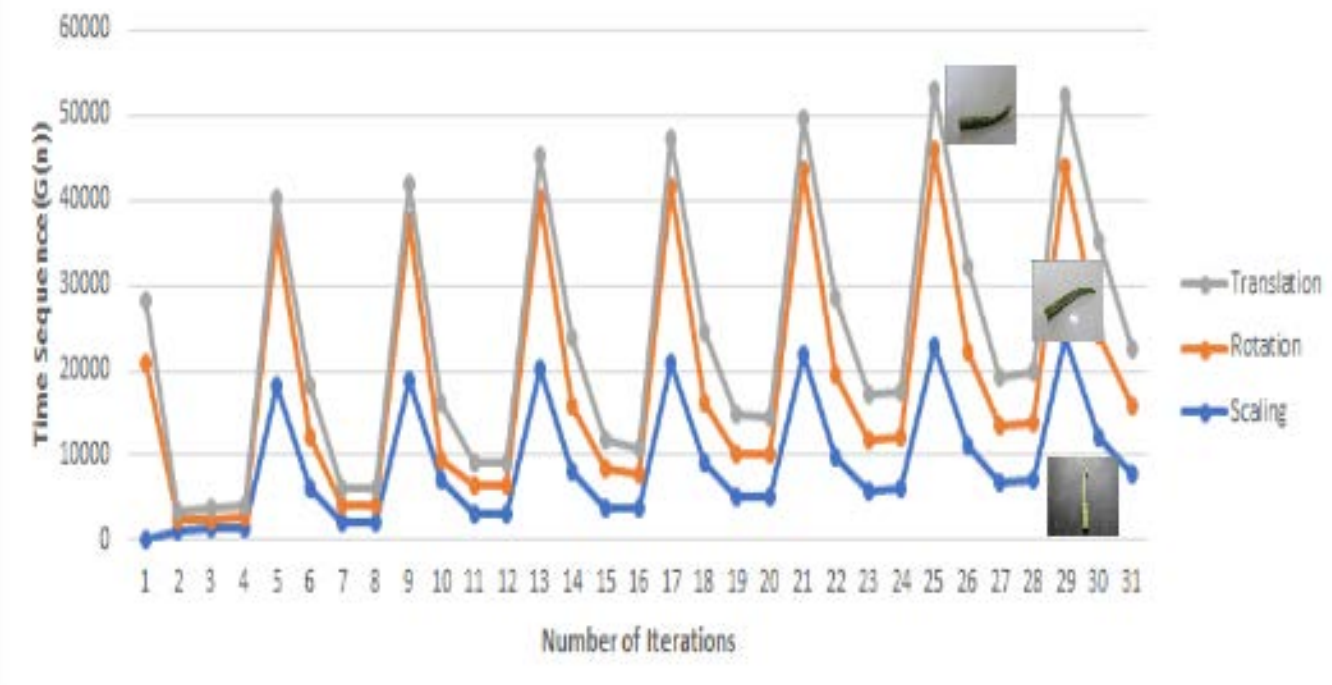

Fig. 5. Translation, rotation and scale invariance

Fig. 6 shows, graphically, the time sequences obtained by our method for the leaf images of the three different species studied, as well as the differences in the features extracted 
between inter-species leaves.The model can distinguish between leaves of different species even though their shapes or characteristics are almost similar. Fig. 7 shows the time sequence obtained by our method for leaf images of three betel species. Though the areas of the leaves are different, their shapes are similar and they belong to the same species. The graph makes it clear that the values are the same and there is little difference over large parts of the graph, indicative of the similarity between intra-species leaves.

Species recognition time includes the time taken to segment the leaf, extract its features and classify it. Our system combines the three processes. The time taken for a leaf to be recognized is 0.34788 seconds with 10 LCFN features in use, 0.61669 seconds with 20 and 0.92401 seconds with 30 . The resultant increased time is because of the time taken for each LCFN iteration. When more features are used, more iterations are required, increasing recognition accuracy. Section 4.2 discusses the recognition accuracy obtained with various combinations of features.

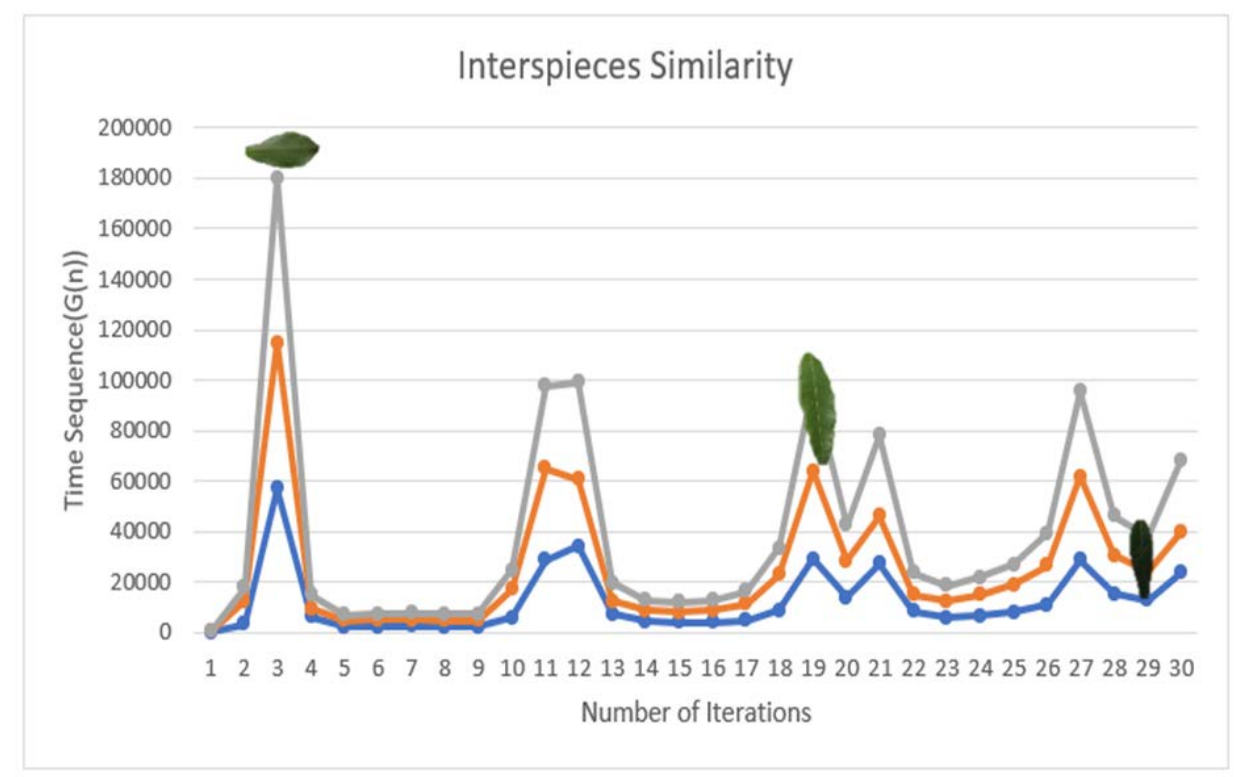

Fig. 6. Interspecies features of mango, insulin herb and nilavembu leaves

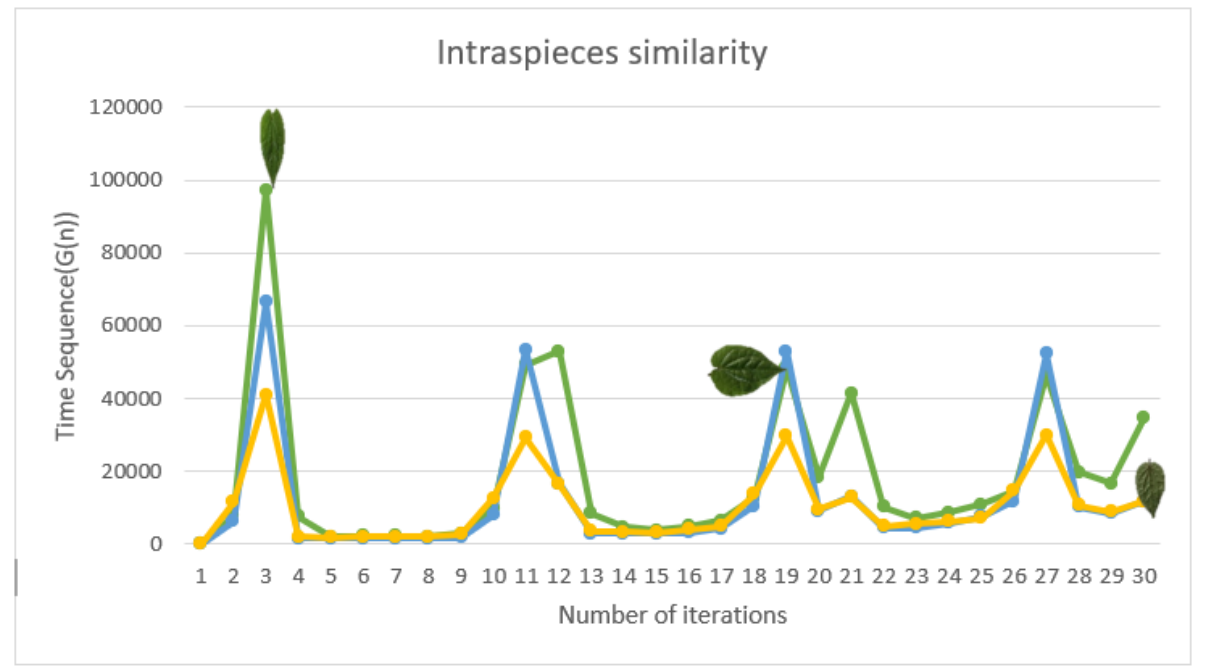

Fig. 7. Intraspecies similarity of betel leaves 


\subsubsection{Geometrical Features}

We fuse LCFN features with geometrical shape features ([25],[26],[27]) such as area, diameter, perimeter, major axis length, minor axis length, Feret diameter, shape factor, aspect ratio, compactness, rectangularity and eccentricity. The definitions and computational methods are shown in Table 2. The geometrical features are extracted and evaluated with the K-NN, SVM, ensemble and BCNN classifiers.

Table 2. Geometrical features

\begin{tabular}{|c|c|c|}
\hline & & \\
\hline Feature & Definition & Computational \\
\hline Diameter (D) & $\begin{array}{l}\text { Diameter measures the } \\
\text { longest distance } \\
\text { between any two points } \\
\text { on the margin. All the } \\
\text { vertex points of a } \\
\text { polygon are determined } \\
\text { by using a convex hull. }\end{array}$ & $\begin{array}{l}\mathrm{D}=\text { Distance between two points } \\
\mathrm{p} 1 \text {, and p2. The pair-wise } \\
\text { distances between each pair of } \\
\text { vertex points are calculated and } \\
\text { the maximum distances between } \\
\text { two vertex points are assigned as } \\
\text { the leaf shape diameter. }\end{array}$ \\
\hline Area & $\begin{array}{l}\text { Area measures the } \\
\text { number of white pixels } \\
\text { in the leaf object. }\end{array}$ & $\begin{array}{l}\text { The total number of white pixels } \\
\text { in the segmented binary image is } \\
\text { counted. }\end{array}$ \\
\hline Perimeter & $\begin{array}{l}\text { Perimeter is the sum of } \\
\text { distances between each } \\
\text { adjacent pair of points } \\
\text { along the outer area of } \\
\text { the blade. }\end{array}$ & $\begin{array}{l}\text { Since the perimeter obtained is } \\
\text { almost continuous, the number of } \\
\text { pixels in the leaf margin is used to } \\
\text { specify the length of the perimeter. }\end{array}$ \\
\hline Major Axis Length & $\begin{array}{l}\text { Major axis length is the } \\
\text { line segment connecting } \\
\text { the base to the tip of a } \\
\text { leaf. }\end{array}$ & $\begin{array}{l}\text { Length of the major axis (in } \\
\text { pixels) }\end{array}$ \\
\hline Minor Axis Length & $\begin{array}{l}\text { Minor axis length is } \\
\text { the maximum width } \\
\text { perpendicular to the } \\
\text { significant axis length. }\end{array}$ & $\begin{array}{l}\text { Length of the minor axis (in } \\
\text { pixels) }\end{array}$ \\
\hline Shape Factor & $\begin{array}{l}\text { A shape factor is a } \\
\text { dimensionless quantity, } \\
\text { independent of leaf } \\
\text { size. Measured by the } \\
\text { area and perimeter of } \\
\text { the leaf, it shows the } \\
\text { circularity of the leaf } \\
\text { shape. }\end{array}$ & Lea $_{s f}=\frac{4 \times \pi \times(\text { Leaf Area })}{\text { Perimeter }^{2}}$ \\
\hline
\end{tabular}




\begin{tabular}{|c|c|c|}
\hline Feret Diameter & $\begin{array}{l}\text { The Feret diameter } \\
\text { measures the size of the } \\
\text { object along a specified } \\
\text { direction. } \\
\text { The maximum pair- } \\
\text { wise distance is } \\
\text { calculated between any } \\
\text { of the vertex points, } \\
\text { v1,v2,v3. }\end{array}$ & leaf $_{F D}=\frac{\text { max distance }}{2 x \sqrt{\text { area } / \pi}}$ \\
\hline Aspect Ratio & $\begin{array}{l}\text { It is the ratio of the } \\
\text { major }(\mathrm{L}) \text { and minor } \\
\text { axis length }(\mathrm{W}) \text {. }\end{array}$ & $\begin{array}{l}\text { Leaf } A R=\text { Length }(L) / \\
\text { width }(\mathrm{W})\end{array}$ \\
\hline Compactness & $\begin{array}{l}\text { Compactness is the } \\
\text { measure of the ratio of } \\
\text { the perimeter to the leaf } \\
\text { area. }\end{array}$ & $C=\frac{\text { Perimeter }}{\sqrt{\text { Area }}}$ \\
\hline Rectangularity & $\begin{array}{l}\text { Rectangularity } \\
\text { represents the nature of } \\
\text { a shape. }\end{array}$ & $\mathrm{R}=$ Area/Length*width \\
\hline Eccentricity & $\begin{array}{l}\text { Eccentricity is the ratio } \\
\text { of the distance between } \\
\text { the foci of the ellipse } \\
\text { and the primary axis } \\
\text { length. It computes zero } \\
\text { for round objects and } 1 \\
\text { for lines. }\end{array}$ & $\begin{array}{l}\mathrm{E}=\text { Foci of ellipse/Major axis } \\
\text { length }\end{array}$ \\
\hline
\end{tabular}




\section{Results and Discussions}

The Indian herb classification model was evaluated by means of various segmentation quality and classification metrics. The quality metrics are explained in this section.

\subsection{Segmenting Herbs using the Chan-Vese Segmentation Method}

The Chan-Vese segmentation results on the herbal leaves studied were analyzed through the overlapping measure between two segments, the pair counting-based metric and the information theoretics-based metric. The quality metrics used were the global consistency error (GCE), Rand index (RI) and the variation of information (VOI).

GCE: The GCE is an error measure between the region of the original image segment ( $\mathrm{R}(\mathrm{S}$ original $)$ ) and the region of the ground truth segment $(\mathrm{R}(\mathrm{S}$ ground truth $))$. The error should be minimum in the particular pixel region (p). Equation (12) measures the error between the two segments.

$$
\operatorname{GCE}\left(S_{\text {original }}, S_{\text {groundtruth }}, p\right)=\frac{\left|R\left(S_{\text {original }}, p\right) \backslash R\left(S_{\text {ground truth }}, p\right)\right|}{\left|R\left(S_{\text {groundtruth }}, p\right)\right|}
$$

RI: The RI is a measure of similarity between two groups of clusters, that is, between the original segmented image ( $\mathrm{S}$ original) and the ground truth image ( $\mathrm{S}$ ground truth). Equation (13) measures the similarity between the two segments. The RI should be at a maximum.

$$
R I\left(S_{\text {original }}, S_{\text {ground truth }}\right)=\frac{a+b}{a+b+c+d}
$$

where $\mathrm{a}$ is the measure of the cardinality of the pixels, $\mathrm{p}_{\mathrm{i}}$ and $\mathrm{p}_{\mathrm{j}}$, placed in the same subset of the two segments, $S$ original and $S$ ground truth; $b$ is the measure of the cardinality of the pixels, $p_{i}$ and $\mathrm{p}_{\mathrm{j}}$, placed in the same subset in the partition $\mathrm{S}$ ground truth, and the pixels $\left(\mathrm{p}_{\mathrm{i}}, \mathrm{p}_{\mathrm{j}}\right)$ are located in different subsets in the partition $\left(S_{\text {original }}\right)$; c is the measure of the cardinality of the pixels, $\mathrm{p}_{\mathrm{i}}$ and $\mathrm{p}_{\mathrm{j}}$, located in the same subset in the partition $\left(S_{\text {original }}\right)$ and the pixels $\left(\mathrm{p}_{\mathrm{i}}, \mathrm{p}_{\mathrm{j}}\right)$ are laid in

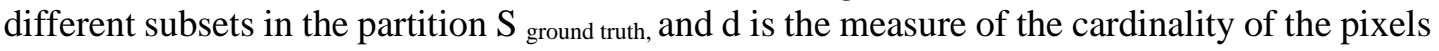
$\left(\mathrm{p}_{\mathrm{i}}, \mathrm{p}_{\mathrm{j}}\right)$ positioned in different subsets of the two partitions, $\mathrm{S}_{\text {original, }}$ and $\mathrm{S}_{\text {ground truth. }}$.

VOI: The VOI is a measure of the amount of information lost or gained between the two segments, $\mathrm{S}_{\text {original }}$ and $\mathrm{S}$ ground truth. Equation (13) measures the VOI between the two segments.

$$
\begin{aligned}
\operatorname{VOI}\left(S_{\text {groundtruth }}, S_{\text {original }}\right) \\
\quad=\operatorname{Entropy}\left(S_{\text {ground truth }}\right)+\operatorname{Entropy}\left(S_{\text {original }}\right) \\
-2 \text { Mutual Information }\left(S_{\text {ground truth }}, S_{\text {original }}\right)
\end{aligned}
$$

Table 3 shows the quality metrics used in the segmentation of the herbal leaves. The ChanVese segmentation algorithm produces minimum error, maximum similarity between clusters and minimal information gain or loss between the two segments. This analysis makes it clear that the region growing active contour segmentation algorithm segments medicinal leaves perfectly. 
Table 3. Segmentation quality metrics of the different herbs

\begin{tabular}{|c|c|c|c|c|c|c|c|c|}
\hline $\begin{array}{c}\text { S.N } \\
\text { o }\end{array}$ & Name & $\begin{array}{l}\text { Input } \\
\text { Image }\end{array}$ & $\begin{array}{l}\text { Grayscale } \\
\text { Image }\end{array}$ & $\begin{array}{l}\text { Binary } \\
\text { Image }\end{array}$ & $\begin{array}{l}\text { Segmented } \\
\text { Image }\end{array}$ & GCE & $\mathbf{R I}$ & VOI \\
\hline 1 & Betel & & & & & 0.0339 & 0.9605 & 0.4112 \\
\hline 2 & Bittergourd & & & & & 0.1024 & 0.8877 & 0.2341 \\
\hline 3 & China Rose & & & & & 0.0459 & 0.9567 & 0.5678 \\
\hline 4 & Grape & & & & & 0.0802 & 0.9790 & 0.3384 \\
\hline 5 & Indian Borage & & & & & 0.0065 & 0.9904 & 0.1660 \\
\hline 6 & Insulin herb & & & & & 0.0446 & 0.9466 & 0.3401 \\
\hline 7 & Mango & & & & & 0.0099 & 0.9858 & 0.2308 \\
\hline 8 & Nilavembu & & & & & 0.0032 & 0.9968 & 0.0352 \\
\hline 9 & Nithiyakalyani & & & & & 0.0379 & 0.9572 & 0.4443 \\
\hline 10 & Pomegranate & & & & & 0.0045 & 0.9841 & 0.1411 \\
\hline
\end{tabular}

\subsection{A Classification Performance Analysis of Indian Medicinal Leaves}

The Indian Medicinal Leaf Species Dataset we created comprises a total of 635 images. Given the limited number of images in each species, we applied data augmentation techniques to increase the number from 635 to 2550 . In all, $70 \%$ of the images were used for training, $10 \%$ for validation and the remaining $20 \%$ for testing. The LCFN features are rotation-, scale- and transform-invariant. Data augmentation, however, helps recognize leaves that have portions missing. Shape features were concatenated with 30 LCFN features and fed to the BRNN classifier to obtain 91.19\% maximum classification accuracy for testing, as shown in Table 4. 
Some preprocessed images were not segmented perfectly, owing to light and shadows. Such images were not classified correctly and produced false negatives that reduced the average accuracy.

The Indian herbs were classified using the Bayesian regularization neural network (BRNN). We applied 5-fold BRNN cross-validation and tested a range of input feature vectors with a number of hidden neurons. We obtained the highest recognition accuracy for a combination of 30 hidden neurons and 41 input feature vectors ( 30 LCFN+11 shape features), as shown in Fig. 7. The performance of the proposed system is evaluated through the metrics of accuracy, precision, true-positive rate (TPR), false-positive rate (FPR), Kappa (K) and Matthew's correlation coefficient with its confusion matrix (Fig. 8).

\section{Classification Accuracy of Medicinal Plants}

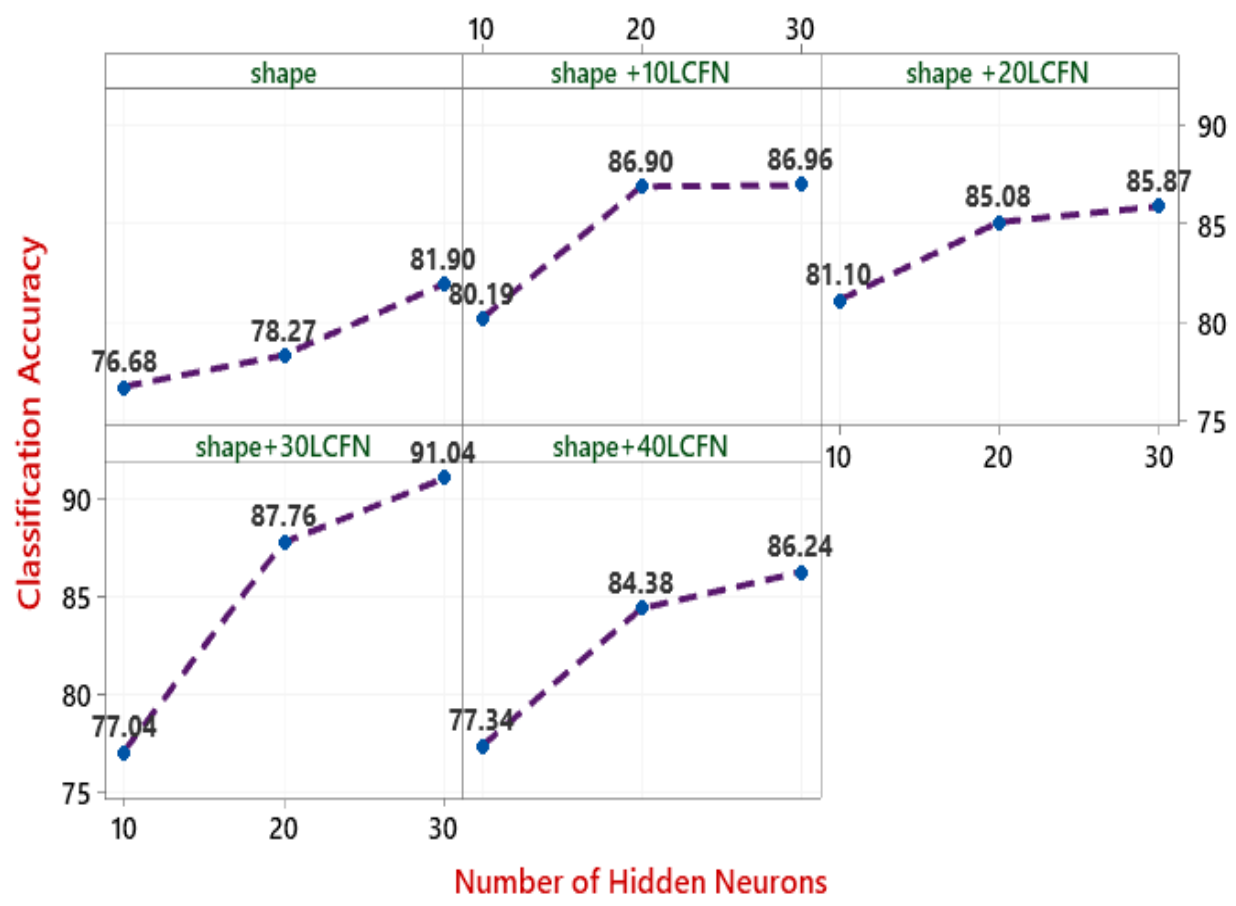

Fig. 7. Classification accuracy of Indian herbs with different hidden neurons

Table 4. Percentage of classification accuracy of Indian herbs

\begin{tabular}{|l|l|l|l|l|}
\hline Classifiers/Features & Shape & $\begin{array}{l}\text { Shape+10 LCFN } \\
\text { features }\end{array}$ & $\begin{array}{l}\text { Shape+20 } \\
\text { LCFN } \\
\text { features }\end{array}$ & $\begin{array}{l}\text { Shape+30 LCFN } \\
\text { features }\end{array}$ \\
\hline K-NN & 70.56 & 83.56 & 82.34 & 84.36 \\
\hline SVM & 73.56 & 75.67 & 80.56 & 82.34 \\
\hline Ensemble classifier & 76.23 & 74.36 & 76.45 & 80.23 \\
\hline BRNN & 80.24 & 84.67 & 86.56 & $\mathbf{9 1 . 1 9}$ \\
\hline
\end{tabular}




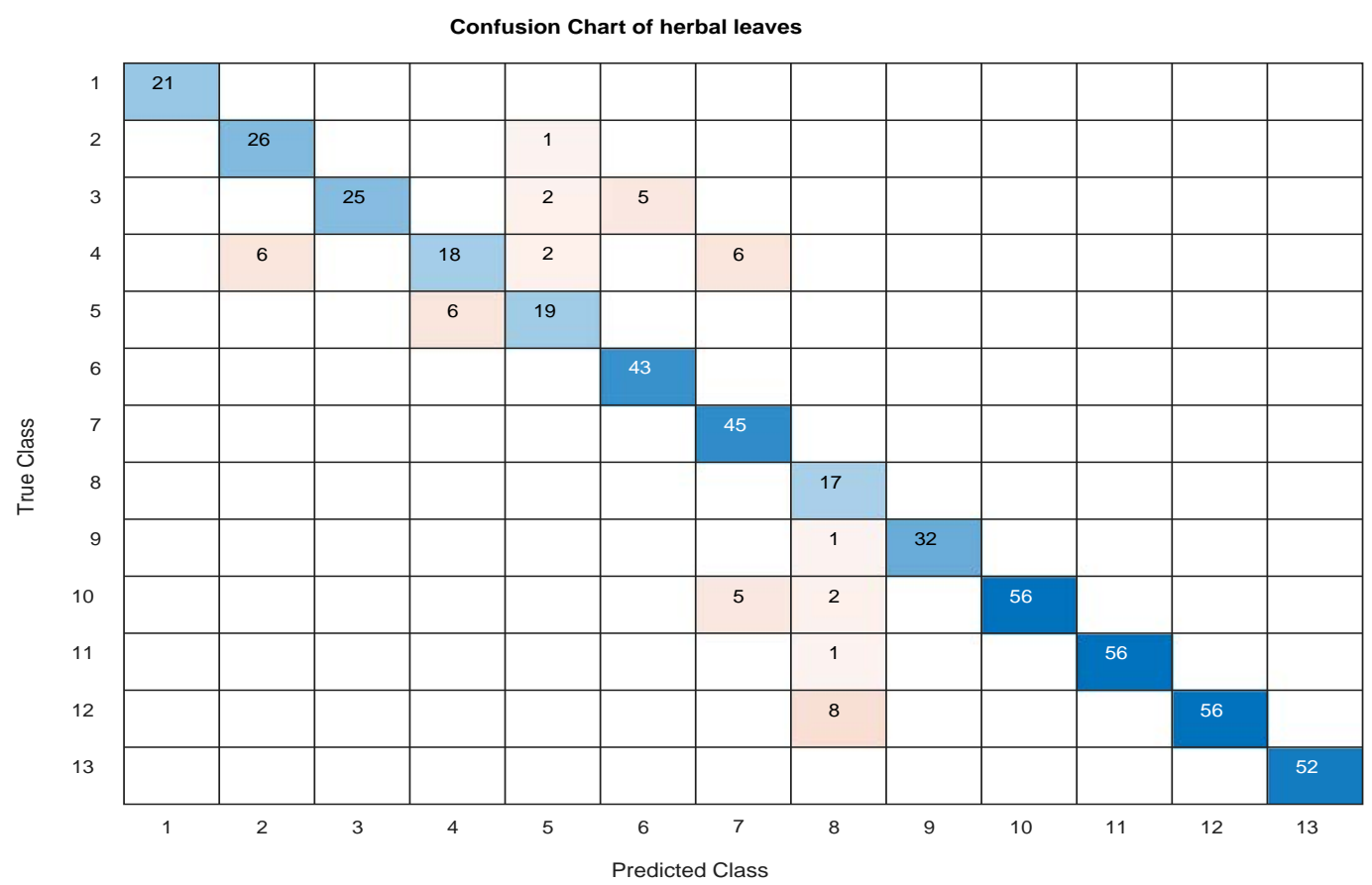

Fig. 8. Confusion matrix for Indian herbs

Table 5 shows a statistical analysis of the 5 -fold neural network classifier. We conclude that our proposed model has produced the highest recognition accuracy of more than $80 \%$ for aloe, betel, bittergourd, grape, guava, mango, nithyakalyani, Indian borage, China rose, sweet basil and pomegranate. Our model has produced a high true positive rate, that is, it correctly classifies all the samples. It classified herbs such as aloe, bittergourd, guava, nilavembu, Indian borage, China rose, sweet basil and pomegranate perfectly. Cohen's kappa is equal to 1 compared to other herbs, and Mattthew's correlation coefficient proves that our model incorrectly predicts the insulin herb and nilavembu leaves.

Table 5. Statistical analysis of the 5-fold neural network classifier

\begin{tabular}{|c|c|c|c|c|c|c|}
\hline Herbal Leaf & Precision & Accuracy & TPR & FPR & Kappa & $\begin{array}{c}\text { Matthew's } \\
\text { Coefficient }\end{array}$ \\
\hline Aloe & 1 & $\mathbf{1}$ & 1 & 0 & 1 & 1 \\
\hline Betel & 0.9630 & $\mathbf{0 . 8 8 1 4}$ & 0.8125 & 0.0345 & 0.7103 & $\mathbf{0 . 7 8 8 2}$ \\
\hline Bittergourd & 0.7813 & $\mathbf{0 . 8 7 7 0}$ & 1.0000 & 0.2188 & 1.0000 & $\mathbf{0 . 7 7 3 0}$ \\
\hline Grape & 0.9000 & $\mathbf{0 . 8 1 8 0}$ & 0.7500 & 0.1000 & 0.5856 & $\mathbf{0 . 6 8 3 3}$ \\
\hline Insulin herb & 0.7600 & 0.7760 & 0.7917 & 0.2400 & 0.6383 & $\mathbf{0 . 6 0 0 0}$ \\
\hline Guava & 1.0000 & $\mathbf{0 . 9 4 5 0}$ & 0.8958 & 0.0000 & 0.8509 & 0.8983 \\
\hline Mango & 1.0000 & $\mathbf{0 . 8 9 1 0}$ & 0.8036 & 0.0000 & 0.7005 & 0.8079 \\
\hline Nilavembu & 1.0000 & 0.7391 & 0.5862 & 0.0000 & 0.2794 & $\mathbf{0 . 6 1 0 5}$ \\
\hline $\begin{array}{c}\text { Nithiya } \\
\text { kalyani }\end{array}$ & 0.9697 & $\mathbf{0 . 9 8 4 6}$ & 1.0000 & 0.0303 & 1.0000 & 0.9688 \\
\hline $\begin{array}{c}\text { Indian } \\
\text { Borage }\end{array}$ & 0.8359 & $\mathbf{0 . 9 1 0 6}$ & 1.0000 & 0.1111 & 1.0000 & 0.8869 \\
\hline China Rose & 0.9825 & $\mathbf{0 . 9 0 3 2}$ & 1.0000 & 0.0175 & 1.0000 & 0.9821 \\
\hline Sweet Basil & 0.8750 & $\mathbf{0 . 9 3 3 3}$ & 1.0000 & 0.1250 & 1.0000 & 0.8728 \\
\hline Pomegranate & 1.0000 & $\mathbf{0 . 8 8 1 4}$ & 1.0000 & 00000 & 1.0000 & 1.0000 \\
\hline
\end{tabular}




\subsection{A Classification Performance Analysis of Herbs from the Flavia Database}

The Flavia database contains 32 Chinese species, each comprising 50-77 images captured with a highly constrained white background. The images were downloaded from https://sourceforge.net/projects/flavia. We selected 32 species of medicinal leaves and tested 1907 images with no data augmentation techniques. In all, 70\% of the images were used for training, $10 \%$ for validation and $20 \%$ for testing and obtained the highest recognition accuracy of $82 \%$ during testing. Our test results were compared with the previous leaf recognition model and found to be not promising. This is because all the images are sample single leaf images of the same size and orientation. Their similarity is, consequently, very high and there is no geometric invariance in the images. Given that our proposed model supports geometrically invariant data, we have changed the image size and orientation to obtain the highest classification accuracy of $97.34 \%$. Table 6(a) shows classification accuracy on the Flavia database with the various $k$ values of the nearest neighbor classifier which, when $k=10$, produces the highest classification accuracy of 90.36\%. Table 6(b) depicts the classification accuracy of the different classifiers and Table 7 their accuracy on the Flavia database. Classification accuracy [26] for shape and color features was 96\%, though the leaf color was found unsuitable for classification.

Table 6(a). Classification accuracy of the different K values of the KNN

\begin{tabular}{|l|l|}
\hline Different K values & Accuracy (shape +30 ICM) \\
\hline $\mathbf{K}=\mathbf{2}$ & 82.46 \\
\hline $\mathbf{K}=\mathbf{4}$ & 85.67 \\
\hline $\mathbf{K}=\mathbf{8}$ & 88.36 \\
\hline $\mathbf{K}=\mathbf{1 0}$ & 90.36 \\
\hline
\end{tabular}

Table 6(b). Classification accuracy of the different classifiers

\begin{tabular}{|c|c|c|c|c|}
\hline Classifiers/Features & Shape & $\begin{array}{c}\text { Shape+10 } \\
\text { LCFN }\end{array}$ & $\begin{array}{c}\text { Shape +20 } \\
\text { LCFN }\end{array}$ & Shape +30 LCFN \\
\hline K-NN (k=10) & 80.56 & 85.56 & 88.34 & 90.36 \\
\hline SVM & 78.56 & 82.67 & 85.56 & 88.34 \\
\hline Ensemble classifier & 74.23 & 78.36 & 81.45 & 84.23 \\
\hline BRNN & 82.24 & 87.67 & 93.56 & 97.34 \\
\hline
\end{tabular}

Table 7. Classification accuracy on the Flavia database

\begin{tabular}{|c|c|c|c|}
\hline Author & Features used & Classifier & Accuracy \\
\hline $\begin{array}{c}\text { Hamid et al. (2019) } \\
\text { [7] }\end{array}$ & $\begin{array}{c}\text { Quartile feature, } \\
\text { leaves are aligned } \\
12 \mathrm{QF}+7 \mathrm{Hu} \\
\text { moment invariant } \\
\text { features }\end{array}$ & $\begin{array}{c}\text { K-fold neural } \\
\text { network classifier } \\
\text { 2- to 20-fold }\end{array}$ & $84.32 \%$ \\
\hline $\begin{array}{c}\text { Chaki et al. (2018) } \\
\text { [9] }\end{array}$ & $\begin{array}{c}12 \mathrm{Hu}+20 \text { shape+144 } \\
\text { texture features, no } \\
\text { evidence of } \\
\text { alignment }\end{array}$ & $\begin{array}{c}\text { Neuro-fuzzy } \\
\text { classifier }\end{array}$ & \\
& $\begin{array}{c} \\
\end{array}$ & & \\
\hline
\end{tabular}




\begin{tabular}{|c|c|c|c|}
\hline $\begin{array}{c}\text { Kolivand et al. } \\
\text { (2019) [13] }\end{array}$ & Venation feature & $\begin{array}{c}10 \text {-fold cross- } \\
\text { validation of the } \\
\text { neural network }\end{array}$ & $98.60 \%$ \\
\hline $\begin{array}{c}\text { Turkoglu et al. } \\
\text { (2019) }\end{array}$ & Texture features & $\begin{array}{c}\text { 10-fold cross- } \\
\text { validation with } \\
\text { extreme learning }\end{array}$ & $98.94 \%$ \\
\hline Pri4] & $\begin{array}{c}\text { 5-fold cross- } \\
\text { validation }\end{array}$ & $97.34 \%$ \\
\hline
\end{tabular}

\section{Conclusion}

This paper has reviewed several plant species classification systems. All the methods used the leaf as the base to classify plant species owing to its two-dimensional nature and availability. All the methods used the leaf as the base to classify plant species owing to its two-dimensional nature and availability. The proposed model handles angular and different-sized images. The model contains only a linking field, and the linking inputs connect faster than the time needed for the decay constant (h) parameter. We tested our system with freshly collected leaves from herbal plants. The results showed that our method avoids normalization and dimension reduction and solves the problem of translation, rotation and scale invariance. Compared to the basic pulse-coupled neural network, the LFCN implemented in this paper uses only three parameters. Though the features extracted depend on the parameter valuethrough the final classification accuracy is influenced by the classifier. Consequently, we tested our method with different classifiers to find that the BRNN provides maximum accuracy. In our future work, the proposed system will be analyzed with an adaptive parameter setting method for the LCFN, depending on image characteristics, through the application of intelligent optimization techniques.

\section{References}

[1] A. N. M. Alamgir, "Pharmacognostical Botany: Classification of medicinal and aromatic plants (MAPs), botanical taxonomy, morphology, and anatomy of drug plants,” Therapeutic Use of Medicinal Plants and Their Extracts: Volume 1, vol. 73, pp. 177-293, 2017.

Article(CrossRef Link)

[2] A. A. Jayeola, "Micromorphological study of plant fragments in some powdered medicinal plants," J. Med. Plants Res., vol. 3, no. 5, pp. 438-442, 2009.

[3] D. C. D. C.H.Arun, "Identifying Medicinal Plant Leaves Using Textures and Optimal Colour spaces Channel,” J. Comput. Sci. Inf., vol. 10, no. 1, pp. 19-28, 2017. Article(CrossRef Link)

[4] Y. G. Naresh and H. S. Nagendraswamy, "Classification of medicinal plants: An approach using modified LBP with symbolic representation,” Neurocomputing, vol. 173, pp. 1789-1797, 2016. Article(CrossRef Link)

[5] D. Shitole, F. Tamboli, and K. M., R. K. Raj, “Ayurvedic Herb Detection using Image Processing,” Int. J. Trend Sci. Res. Dev., vol. Vol. 3, no. 4, pp. 491-494, 2019. Article(CrossRef Link)

[6] J. R. Xue et al., "Automated Chinese medicinal plants classification based on machine learning using leaf morpho-colorimetry, fractal dimension and visible/near infrared spectroscopy,” Int. J. Agric. Biol. Eng., vol. 12, no. 2, pp. 123-131, 2019. Article(CrossRef Link)

[7] L. E. Hamid and S. A. R. Al-Haddad, “Automated leaf alignment and partial shape feature extraction for plant leaf classification,” Electron. Lett. Comput. Vis. Image Anal., vol. 18, no. 1, pp. 37-51, 2019. Article(CrossRef Link)

[8] A. Aakif and M. F. Khan, "Automatic classification of plants based on their leaves," Biosyst. Eng., vol. 139, pp. 66-75, 2015. Article(CrossRef Link) 
[9] J. Chaki, R. Parekh, and S. Bhattacharya, "Plant leaf classification using multiple descriptors: A hierarchical approach,” J. King Saud Univ. - Comput. Inf. Sci., vol. 32, no. 10, pp. 1158-1172, 2020. Article(CrossRef Link)

[10] J. Y. CLARK, D. P. A. CORNEY, and P. WILKIN, "Leaf-based Automated Species Classification Using Image Processing and Neural Networks,” Biological Shape Analysis, pp. 29-56, 2017. Article(CrossRef Link).

[11] H. Wang, D. Tian, C. Li, Y. Tian, and H. Zhou, "Plant leaf tooth feature extraction," PLoS One, vol. 14, no. 2, Feb. 2019. Article(CrossRef Link)

[12] M. M. S. de Souza, F. N. S. Medeiros, G. L. B. Ramalho, I. C. de Paula, and I. N. S. Oliveira, "Evolutionary optimization of a multiscale descriptor for leaf shape analysis," Expert Syst. Appl., vol. 63, pp. 375-385, Nov. 2016. Article(CrossRef Link)

[13] H. Kolivand, B. M. Fern, T. Saba, M. S. M. Rahim, and A. Rehman, "A New Leaf Venation Detection Technique for Plant Species Classification,” Arab. J. Sci. Eng., vol. 44, no. 4, pp. 33153327, 2019. Article(CrossRef Link)

[14] M. Turkoglu and D. Hanbay, "Leaf-based plant species recognition based on improved local binary pattern and extreme learning machine,” Phys. A Stat. Mech. its Appl., vol. 527, 2019. Article(CrossRef Link)

[15] S. Zhang, C. Zhang, and X. Wang, "Plant species recognition based on global-local maximum margin discriminant projection,” Knowledge-Based Syst., vol. 200, p. 105998, 2020, Article(CrossRef Link).

[16] X. Deng, C. Yan, and Y. Ma, “PCNN Mechanism and its Parameter Settings,” IEEE Trans. Neural Networks Learn. Syst., vol. 31, no. 2, pp. 488-501, 2020. Article(CrossRef Link)

[17] K.K.Thyagharajan, I.Kiruba Raji, "A Review of Visual Descriptors and Classification Techniques used in Leaf Spieces Identification," Archieves of Computational Methods in Engineering, vol. 26, no. 4, pp. 933-960, 2019. Article(CrossRef Link)

[18] T. F. Chan and L. A. Vese, “Active Contours Without Edges," IEEE Transactions on Image Processing, vol. 10, no. 2, pp. 266-277, 2001. Article(CrossRef Link).

[19] X. F. Wang, D. S. Huang, and H. Xu, “An efficient local Chan-Vese model for image segmentation,” Pattern Recognit., vol. 43, no. 3, pp. 603-618, 2010. Article(CrossRef Link)

[20] I. Kiruba Rajia and K. K. Thyagharajan, “An analysis of segmentation techniques to identify herbal leaves from complex background,” Procedia Comput. Sci., vol. 48, no. C, pp. 589-599, 2015. Article(CrossRef Link)

[21] Y. Yuan, Y.-W. Chen, C. Dong, H. Yu, and Z. Zhu, "Hybrid method combining superpixel, random walk and active contour model for fast and accurate liver segmentation,” Comput. Med. Imaging Graph., vol. 70, pp. 119-134, Dec. 2018. Article(CrossRef Link)

[22] P. Getreuer, “Chan-Vese Segmentation,” Image Process. Line, vol. 2, pp. 214-224, 2012. Article(CrossRef Link)

[23] R. Eckhorn, H. J. Reitboeck, M. Arndt, and P. Dicke, "Feature Linking via Synchronization among Distributed Assemblies: Simulations of Results from Cat Visual Cortex,” Neural Comput., vol. 2, no. 3, pp. 293-307, 1990. Article(CrossRef Link)

[24] J. L. Johnson, "Pulse-coupled neural nets: translation, rotation, scale, distortion, and intensity signal invariance for images,” Appl. Opt., vol. 33, no. 26, p. 6239, Sep. 1994. Article(CrossRef Link)

[25] C. A. Priya, T. Balasaravanan, and A. S. Thanamani, "An efficient leaf recognition algorithm for plant classification using support vector machine,” in Proc. of Int. Conf. Pattern Recognition, Informatics Med. Eng. PRIME 2012, pp. 428-432, 2012. Article(CrossRef Link)

[26] A. Caglayan, O. Guclu, and A. B. Can, “A plant recognition approach using shape and color features in leaf images,” Lect. Notes Comput. Sci. (including Subser. Lect. Notes Artif. Intell. Lect. Notes Bioinformatics), vol. 8157 LNCS, no. PART 2, pp. 161-170, 2013. Article(CrossRef Link)

[27] J. Hossain and M. A. Amin, "Leaf shape identification based plant biometrics,” in Proc. of 2010 13th Int. Conf. Comput. Inf. Technol. ICCIT 2010, no. Iccit, pp. 458-463, 2010. Article(CrossRef Link). 


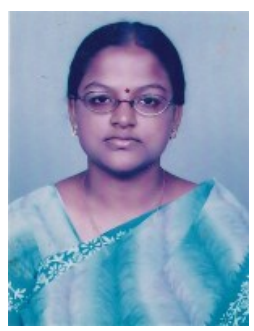

I.Kiruba Raji received her B.E degree in Madurai Kamaraj University in the year 2004 and received her M.E degree in Anna University in the year 2006. Currently, she is pursuing her Ph.D. at Anna University. She published 8 papers in various international journals.

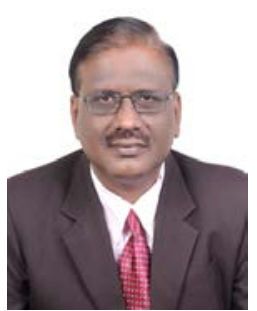

Dr.K.K. Thyagharajan received his B.E. in Electrical and Electronics Engineering from PSG College of Technology in 1986 and M.E. in Applied Electronics from Coimbatore Institute of Technology, India in 1988. He also possesses a Post Graduate Diploma in Computer Applications from Bharathiar University, India. He obtained his Ph.D. degree in Information and Communication Engineering from Anna University in 2007. He is in teaching profession for more than three decades and served as Professor, Principal and Dean at various Engineering Colleges. Now he is Dean (Research) at RMD Engineering College. He has written 5 books in Computing including Flash MX 2004 published by McGraw Hill. He is reviewer and editorial board member for many International Journals and Conferences, and recognized Ph.D. supervisor. He has published more than 100 papers in International Journals. He has six patents published to his credit. His research interests include Computer Vision, Semantic Web, Image \& Video Processing, Multimedia Streaming, Video Coding, Content-based Information Retrieval, Microcontrollers and e-learning. He is a Fellow of Institution of Engineers (India).

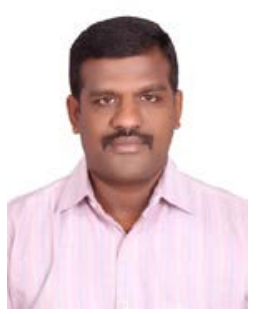

Dr.T.VIGNESH obtained his M.Tech and Ph.D degree at Manonmaniam Sundaranar University in the year respectively 2011 and 2019. He has 10 plus years of teaching experience and 3 years of Industry Experience. Now he is working as an Associate professor Department of Computer Science and Engineering, APEX Institute of Technology, Chandigarh University, Mohali, Panjab, India. He has published 28 research papers in various national and international conferences and journals. His current research areas are Satellite Image Processing, Pattern Recognition, Soft Computing research and Human action recognition. He is a lifetime member of various international professional bodies such as ISTE, IAENG and IACSIT.

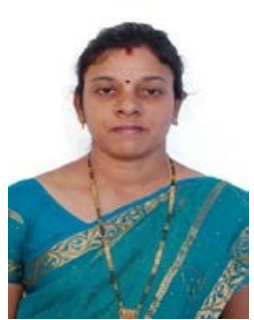

Dr. G.Kalaiarasi has received her B.Tech., degree in Information Technology from Srinivasa Institute of Engineering \& Technology affiliated to Madras University. She has completed M.E., in Computer Science \& Engineering Dhanalakshmi Srinivasan Engineering College which is affiliated to Anna University. She obtained her Ph.D., degree in Information \& Communication Engineering, Anna University, Chennai. She has published papers in National \& International Journals and Conferences. Her research areas are Computer Vision, Image Processing, Image Retrieval, Content Based Multimedia Retrieval and Data Mining. She has served at various Educational Institutions. She has more than ten years of teaching experience. Currently she is working in Sathyabama Institute of Science and Technology. 